\title{
Analisis Standar Kelayakan Kapal Melalui Annual Survey (Studi Kasus Kapal UB. Istana Laut) di PT. Makara Jaya Marine
}

\author{
Vidya Selasdini ${ }^{1}$, Marthauli Trinita ${ }^{2}$ \\ ${ }_{1,2}$ Prodi Ketatalaksanaan Angkutan Laut dan Kepelabuhanan \\ Sekolah Tinggi Ilmu Pelayaran, Jakarta \\ Jl. Marunda Makmur No. 1 Cilincing, Jakarta Utara. Jakarta 14150
}

\begin{abstract}
Abstrak
Dalam pengoperasian kapal diperlukan keselamatan sesuai peraturan internasional dan peraturan nasional mengenai kelayakan kapal. Penelitian ini mengkaji tentang penyebab kerusakan pada permesinan di kapal UB. Istana Laut dan upaya yang dilakukan oleh personil kapal untuk memenuhi standar keselamatan kapal. Metode yang digunakan dalam penelitian ini adalah deskriptif kualitatif. Dari hasil penelitian diperoleh kesimpulan bahwa kerusakan yang terjadi pada permesinan kapal di kapal UB. Istana Laut disebabkan oleh bocornya bagian kanan mesin utama pada turbo charge dan indikator lampu emergensi pada mesin penyuplai daya tidak bekerja saat di test. Upaya yang dilakukan oleh personil kapal untuk memenuhi standar keselamatan adalah melakukan perawatan secara periodik menurut waktu kalender untuk penanganan longgarnya selang pemadam kebakaran dan membuat matrix daftar peralatan yang memiliki masa expired untuk penangannya baterai EPIRB dan HRU yang telah expired.
\end{abstract}

Copyright $($ ) 2020, Prosiding Seminar Pelayaran dan Riset Terapan

Kata Kunci: analisis, kelayakan, annual survey

Permalink/DOI : https://doi.org/10.36101/pcsa.v2i1.130

\section{PENDAHULAN}

Dalam aktivitas ekploitasi hasil minyak dan gas bumi ada dua kegiatan, yaitu onshore dan offshore. Onshore ialah bangunan atau struktur yang dibangun di daratan dengan sebagai penopang kegiatan proses ekplorasi dan eksploitasi minyak dan gas bumi. Sedangkan offshore adalah bangunan atau struktur yang di bangun dia atas laut dengan kedalaman tertentu.

Kebutuhan kapal kontruksi lepas pantai (offshore) di Indonesia di prediksi akan terus meningkat tiap tahunnya di dukung oleh lonjakan aktivitas eksplorasi minyak dan gas di Tanah Air. Data dari Indonesia National Shipowners' Association menyatakan bahwa aktivitas offshore di Indonesia terus meningkat secara bertahap sepanjang tahun 2017 dan akan terus meningkat pada tahun 2018.

Dalam pengoperasian kapal diperlukan keselamatan sesuai peraturan internasional dan peraturan nasional mengenai kelayakan kapal. PT. Makara Jaya Marine, yang mana bergerak dalam kegiatan pengecekan kapal dengan melakukan pemeriksaan (survei) di bidang offshore marine dan engineering consultant, mengacu pada peraturan internasional seperti SOLAS 2010, MARPOL 73/78, ILO, STCW, IMCA dan peraturan nasional seperti UU No. 1 Tahun 1970 tentang Keselamatan Kerja, Permenaker No. 4 Tahun 1995, Instruksi Menteri RI No. 5 Tahun 1996, dan Permenaker No. 5 Tahun 1996 serta PP No. 51 Tahun 2002 tentang Perkapalan.

Dalam dunia offshore, survey sangat penting. Kesalahan data lingkungan sedikit saja kan berakibat fatal, misalnya pipa yang bocor, lampu pelampung tidak menyala dan lain sebaginya. Karena itulah perusahaan survey berperan penting disini.

Untuk memenuhi standar internasional keselamatan bagi semua kapal yang akan dioperasikan diperlukan kepastian kondisi kapal melalui kegiatan survey besar guna mendapatkan kelayakan kapal. Berdasarkan peraturan tenteng keselamatan pelayaran seperti SOLAS, maka prinsip dasar kelayakan kapal diwajibkan kepada setiap kapal baru maupun bekas pakai yang hendak dioperasikan. Untuk mengetahui sejauh mana kelayakan kapal dipersyaratkan dan bagaimana memenuhi persyaratan keselamatan tersebut maka kegiatan survey tahunan meliputi pengecekan terhadap beberapa aspek pekerjaan, yang antara lain :

1. Suitability Survei (Condition Survei, Suitability Survei, IMCA M149, IMCA M189, OVID) 
2. On - Off Hire Consumable Survei, On - Off Hire Condition Survey

3. Load Out, Transportation \& Installation (Stowage and Lashing)

4. Pre - Towage \& Towage Approval

5. Rig Mover, Rig Move MWS, Marine Representative

6. Bunker Transfer Approval

7. Damage Survei

8. Pre - Purchase/ Valuation, P\&I, H\&M ( P \& I Pre - Entry Survei, P\&I Survei)

9. Marine Consultancy

10. Engineering (Analysis Investigation, Mooring Analysis, Mooring Assessment, Lifting Stability)

Bahwa dari 10 (sepuluh) aspek pekerjaan diatas peneliti fokus terhadap pekerjaan nomor 1 (satu), yaitu suitability survey tentang IMCA M149. Untuk menjamin kepastian akan kelayakan kapal-kapal yang akan digunakan tersebut maka perusahaan-perusahaan pelayaran memerlukan bukti nyata (berupa laporan survey) dari surveyor dibidang marine dan engineering antara lain PT. Makara Jaya.

Peningkatan pemeriksaan terhadap kelayakan kapal agar sesuai dengan persyaratan keselamatan dalam berlayar adalah kegiatan IMCA Survey. Program survey ini diberlakukan untuk mencegah terjadinya kecelakaan yang disebabkan oleh sistem pemeliharaan yang tidak memenuhi persyaratan keselamatan pelayaran. Untuk itu peneliti mengidentifikasi beberapa masalah yang biasanya ditemukan dalam IMCA M149 Survey (khusus kapal yang memiliki gross tonnage diatas 500) sebagai berikut :

1. Adanya kerusakan pada permesinan di kapal UB. Istana Laut

2. Sistem alat keselamatan di kapal belum memadai

3. Pemahaman tentang sistem emergency kapal kurang

4. Alat keselamatan kapal tidak memenuhi standar

Mengingat luasnya permasalahan dalam pemenuhan kelayakan kapal sebagai persyaratan keselamatan pelayaran maka peneliti memberikan batas masalah yaitu sejauh mana peran IMCA M149 Survey dapat berpengaruh dalam menunjang kelayakan kapal sebelum dioperasikan agar dapat berlayar dengan aman dan sesuai standar keselamatan. Karena keterbatasan waktu maka peneliti hanya akan membahas dua masalah, yaitu:

1. Adanya kerusakan pada permesinan di kapal UB. Istana Laut

2. Alat keselamatan kapal tidak memenuhi standar
Untuk dapat menganalisis dan memecahkan masalah suatu perusahaan, ada beberapa hal yang peneliti angkat dalam penelitian ini melalui rumusan masalah sebagai berikut :

1. Apakah yang menyebabkan kerusakan pada permesinan kapal di kapal UB. Istana Laut?

2. Apakah upaya yang dilakukan oleh personil kapal untuk memenuhi standar keselamatan kapal?

Kemudian tujuan dilaksanakannya penelitian ini yaitu:

1. Untuk mengetahui dan menganalisis standar kelayakan kapal yang belum terpenuhi

2. Untuk memberikan rekomendasi melalui cara atau model penangguhan standar kelayakan

\section{METODE}

Metode Pendekatan yang digunakan dalam penelitian ini adalah metode pendekatan deskriptif kualitatif. Dalam memperoleh data peneliti menggunakan teknik pengumpulan data berupa observasi. Observasi adalah pengumpulan data berupa informasi berdasarkan pengamatan langsung oleh peneliti di PT. Makara Jaya Marine.

\section{HASIL DAN PEMBAHASAN}

PT. MAKARA JAYA MARINE melakukan kegiatan survey kapal yang biasanya beroperasi di pekerjaan lepas pantai (Offshore marine / ship surveyor). Surveyor melakukan pemeriksaan, penelitian, dan pengawasan atas suatu kapal atau yang berhubungan dengan kemaritiman lepas pantai baik di dalam maupun di luar negeri.

Sehubungan dengan lamanya perusahaan ini berdiri, perusahaan ini terbilang sudah berkembang. Pihak yang selama ini menggunakan jasa PT. Makara Jaya Marine umumnya adalah perusahaan-perusahaan yang melakukan kegiatan eksplorasi lepas pantai, on-off hire, bunker, atau perusahaan pemilik atau perusahaan asuransi yang kapalnya mengalami kecelakaan.

Sebagai perusahaan yang bergerak dibidang bisnis jasa survey, perusahaan ini memiliki pelayanan untuk berbagai survey yang dibutuhkan kapal, adapun survey yang tersedia yaitu, survey kelayakan kapal untuk offshore, survey yang menilai kondisi kapal sebelum dan sesudah di sewa, survey pengikatan barang di kapal, pengawasan proses pengisian bahan bakar kapal, survey P\&I, konsultasi tentang kelautan, konsultasi tentang permesinan kapal, dan konsultan peletakan pipa untuk pengeboran lepas pantai.

Dari banyaknya klien PT. Makara Jaya Marine, peneliti mengambil sample dari kapal Utility Boat milik PT. Barokah Gemilang Perkasa bernama Istana Laut. Kapal ini mulai beroperasi pada tahun 2011, kapal ini disurvey karena akan 
digunakan oleh PHE ONWJ untuk pengiriman bahan material dan pertukaran awak kapal di offshore.

International Marine Contractors Association atau IMCA memiliki berbagai macam tipe survey IMCA, namun PT. Makara Jaya Marine hanya menggunakan 2 macam tipe survey IMCA yaitu IMCA 149 dan IMCA 189. Perbedaan antara kedua survey tersebut terletak dalam besar kecilnya kapal yang akan di survey. IMCA 149 digunakan sebagai dasar untuk memeriksa kapal yang berukuran lebih dari $500 \mathrm{GT}$ atau panjang kapal lebih dari 24 meter. Sedangkan IMCA 189 digunakan untuk memeriksa kapal yang berukuran kurang dari 500 GT atau panjang kapal yang kurang dari 24 meter.

Untuk itu kapal UB Istana Laut yang memiliki panjang 39,2 meter dan ukuran 490 GT menggunakan jenis survey IMCA 149 yang dimana salah satu syaratnya telah terpenuhi yaitu panjang kapal lebih dari 24 meter.

Pada form ketentuan dalam IMCA M149 terdapat 18 jenis bab dengan perincian sebagai berikut:

1) Vessel Particular

Berisikan tentang rincian data kapal lengkap sebagai identitas kapal termasuk data general, data machinery, data hull, data owner kapal, dan lainlain. Vessel particular sebagai data diri sebuah kapal yang singkat dan lengkap sehingga memudahkan kita untuk mengetahuinya dengan mudah.

2) Previous Inspection

Berisikan pertanyaan mengenai status kapal yang sudah atau belum pernah melaksanakan pemeriksaan dari Port State Control (syahbandar) pada inspeksi sebelumnya.

3) Certificates

Berisikan pertanyaan seputar sertifikat apa saja yang berlaku dan apakah sertifikat telah di periksa dan di verifikasi oleh Inspektor.

4) Index of Certificates

Berisikan tabel daftar sertifikat yang berlaku di kapal dan tanggal sertifikat akan exprired serta referensi sertifikat.

\section{5) Safety Management System}

Berisikan pertanyaan tentang keselamatan dan keamanan kerja untuk mengurangi resiko kecelakaan kerja agar tercipta lingkungan kerja yang aman dan produktif, bahasa yang digunakan diatas kapal, penggunaan obat terlarang dan alcohol, serta manajemen keselamatan yang dilakukan oleh para awak kapal.

6) Health, Safety, and Environment (HSE)

Berisikan pertanyaan tentang bagaimana usaha untuk mencegah kemungkinan terjadinya kecelakaan dan penyakit akibat kerja. Pelatihan prosedur emergensi. Tujuannya untuk memberikan jaminan keselamatan dan kesehatan kerja agar memudahkan operasional kapal.

7) Security

Pertanyaan tentang workboat yang diperlukan memenuhi rencana keamanan kapal yang disetujui untuk memenuhi persyaratan dalam ISPS.

8) Crew Management

Berisikan pertanyaan mengenai standar kualifikasi awak kapal. Apakah awak kapal memiliki sertifikat atau keahlian yang dibutuhkan di kapal tersebut.

9) Crew Qualifications

Tabel yang berisikan daftar nama awak kapal mulai dari kapten kapal hingga koki kapal dan kualifikasi serta sertifikat standar yang dimiliki oleh para awak kapal.

10) Life-saving Appliances (LSA)

Pada bab ini terdapat pertanyaan mengenai tersedianya rakit penolong di kapal yang cukup untuk penumpang maksimum di atas kapal yang diusulkan, rakit penolong memiliki sertifikat saat pemeriksaan, tersedianya pelampung keselamatan yang cukup, jaket keselamatan yang dapat mengapung di atas ombak, tersedianya jaket keselamatan untuk setiap orang, tersedianya parasut tahan api, ada tidaknya sinyal asap apung atau obor, tersedianya jaket pelindung panas untuk setiap orang yang ada di atas kapal, tabel sinyal keselamatan, cara yang efektif untuk memulihkan orang yang tenggelam, cara menbunyikan alarm umum yang berfungsi dengan baik dalam keadaan darurat, tersedianya panduan pelatihan untuk penggunaan peralatan keselamatan (LSA), instruksi untuk pemeliharaan LSA, terpelihara atau tidaknya catatan latihan darurat, serta tersedianya panduan/rencana tanggap darurat secara berkala.

11) Firefighting Appliances

Berisikan pertanyaan seputar peralatan pemadam kebakaran. Terdapat pertanyaan mengenai alat pemadam kebakaran yang sesuai dengan peraturan yang berlaku, selang pemadam kebakaran yang telah rusak, ketersediaan daftar pemeliharan peralatan pemadam kebakaran, sistem pendeteksi gas, pengetahuan awak kapal tentang keadaan emergensi, buku manual LSA dan lainlain.

\section{2) Pollution Prevention}

Berisikan pertanyaan tentang pencegahan pencemaran terhadap lingkungan dari setiap kegiatan pengoperasian kapal. Bagaimana perencanaan pembuangan sampah pada kapal dan pembuangan air ballas.

13) General Appreance

Berisikan pertanyaan tentang penampilan umum kapal, mulai dari kondisi deck kapal, kondisi dapur, kondisi klinik kapal, hingga apakah kapal terbebas dari serangga. 
14) Bridge, Navigation and Communications

Equipment

Berisikan pertanyaan yang berkaitan dengan kebijakan operator serta instruksi dan prosedur yang berkaitan dengan navigasi yang aman, peringatan navigasi dan prakiraan cuaca terbaru.

\section{5) Machinery Space}

Berisikan pertanyaan tentang keadaan mesin/generator yang ada di kamar mesin, kebersihan kamar mesin yang terbebas dari kebocoran dan mesin terbebas dari kerusakan.

16) Mooring, Towing and Lifting Equipment

Berisikan pertanyaan tentang keadaan alat untuk menambatkan kapal pada satu titik agar tidak bergerak yang disebut mooring, alat untuk menarik kapal yang disebut towing dan alat angkat yang digunakan untuk mengangkat beban dengan kapasitas tertentu yang disebut lifting equipment dalam keadaan layak untuk digunakan.

17) Construction and Stability

Berisikan pertanyaan mengenai adakah buku panduan sebagai bahan referensi tentang konstruksi dan stabilitas kapal.

18) Offshore Supply Vessel (OSVs)

Berisikan pertanyaan seputar kegunaan kapal sebagai kapal pensuplay di kegiataan offshore. Mulai dari penanganan kargo, area dek kargo higga adakah tank kargo didalam kapal.

Dalam kegiatan survey, ada 3 (tiga) prosedur yang harus dilakukan oleh perusahaaan pemilik kapal dan surveyor yang akan menginspeksi kapal, prosedur tersebut yaitu ;

1. Prosedur permintaan survey

2. Prosedur pelaksanaan survey

3. Prosedur pengiriman laporan survey

Dari hasil full report, ada 18 bab yang berisikan berbagai macam pertanyaan ini (total 169 pertanyaan), surveyor merangkumnya berdasarkan tinjauan akan kondisi kapal serta pertimbangan akan prioritas yang harus ditangani oleh client terhadap kapalnya. Maka pada kasus kapal UB Istana Laut didapati ada 16 temuan yang telah dirangkum menjadi laporan sementara (summary report) dan dikim dalam waktu 1 x 24 jam terhitung dari proses setelah inspeksi dilaksanakan sesuai dengan ketentuan yang terdapat di dalam kontrak kerja. Summary report yang mana laporan ini sebelum dikirim harus di QC (Quality Control) terlebih dahulu oleh Marine Manager dan setelah dipastikan laporannya sudah sesuai maka bagian administrator dapat mengirim laporan tersebut melalui email kepada pihak client (PT. Barokah Gemilang Perkasa).

Berdasarkan Data Summary Report PT. Makara Jaya Marine pada Kasus Kapal UB. Istana Laut, dapat digambaran prosentasenya dengan diagram sebagai berikut :

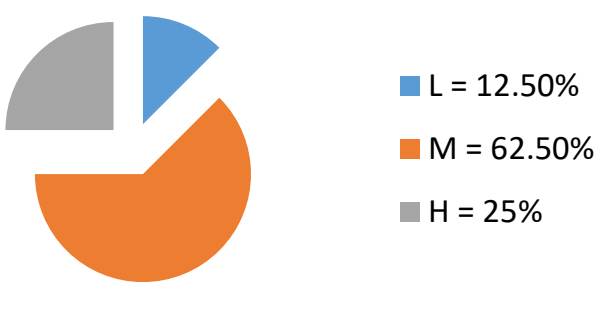

Gambar 1. Diagram Prosentase Kekurangan Berdasarkan Prioritas

Dari Gambar 1 dapat disimpulkan bahwa proritas low yang mana penanganannya tidak wajib untuk dilakukan (optional) ada 2 nomor bernilai $12.50 \%$. Sedangkan untuk prioritas medium ada 10 nomor hasil penanganan bernilai $62.50 \%$ dan penangannya diberi batas waktu dalam 90 hari. Untuk prioritas high terdapat 4 nomor hasil pengamaan bernilai $25 \%$, namun dalam prioritas high penanganannya harus segera dilaksanakan karena sangat serius untuk dilakukan tindakan.

Setelah laporan summary dikirim, proses selanjutnya adalah pembuatan laporan IMCA full report atau secara lengkapnya. Pembuatan laporan dibuat 7x24 jam setelah survey dilakukan. Prosesnya juga sama dengan pengiriman summary, setelah surveyor membuat IMCA full report maka dilakukan pemeriksaan kualitas (QC) oleh Marine Manager. Setelah itu Administrator mengirim softcopy laporan secara lengkap melalui email, dan mengirim dalam bentuk hardcopy kepada client yaitu PT.Barokah Gemilang Perkasa. Ada beberapa catatan dari laporan IMCA tersebut yang harus dilaksanakan oleh client sebelum kapal dioperasikan. Hasil laporan lengkap survey ini akan memberikan rekomendasi kepada client untuk melakukan perbaikan.

Berdasarkan deskripsi data yang telah dijelaskan sebelumnya mengenai permasalahan yang diangkat, peneliti mengambil 4 masalah yang sangat vital, "Life-saving Appliances" dan "Machinery Space".

1. Adanya kerusakan pada permesinan kapal di kapal UB. Istana Laut

Dalam bab 15 yang membahas tentang "Machinery Space" yaitu bab yang membahas seputar hal-hal yang berada di ruang mesin, peneliti membahas 2 masalah yaitu :

a. Bagian kanan mesin utama pada turbo charge mengalami kebocoran (tabel 4.2 audit item, section 15.1)

Di dalam pengoperasian kapal, Turbocharge sering digunakan pada mesin pembakaran yang berfungsi memaksimalkan keluaran tenaga mesin berupa gas buang sehingga menambah efesiensi mesin dengan melakukan penambahan tekanan dan jumlah udara yang masuk kedalam mesin. Ketika turbo charge mengalami 
kebocoran, akibatnya adalah akan terjadi kebakaran bahkan ledakan.

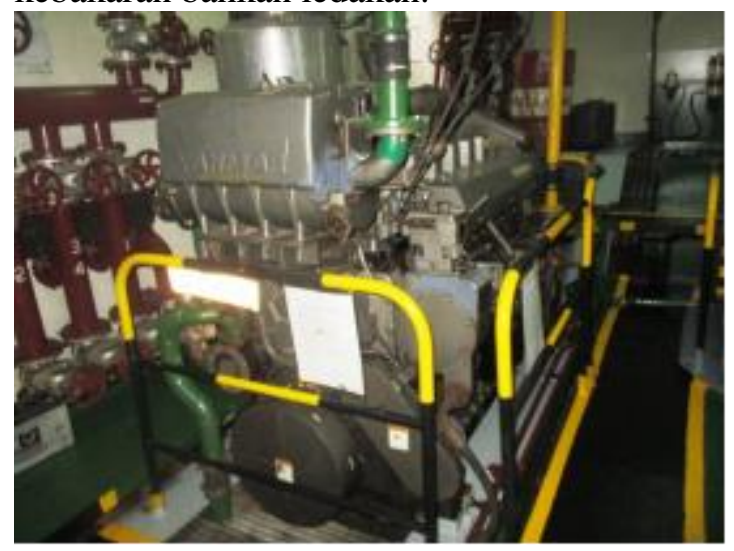

Gambar 2. Main Engine

Untuk dapat menjelaskan mengenai penyebab terjadinya kebocoran dan bagaimana penangulangannya maka peneliti melakukan pengamatan terhadap pengoperasian dan mewawancarai bebrapa awak kapal, surveyor yang dirangkum dalam tabel seperti berikut.

Tabel 2. Analisa Data Wawancara

\begin{tabular}{|c|l|l|}
\hline Profesi & Penyebab Kebocoran & \multicolumn{1}{|c|}{$\begin{array}{c}\text { Cara } \\
\text { Memperbaiki }\end{array}$} \\
\hline $\begin{array}{c}\text { Surveyor } \\
1\end{array}$ & $\begin{array}{l}\text { Kerusakan mekanisme } \\
\text { yang disebabkan } \\
\text { karena kurangnya } \\
\text { pelumasan }\end{array}$ & $\begin{array}{l}\text { Menambah } \\
\text { jumlah pelumas } \\
\text { sesuai dengan } \\
\text { standar yang } \\
\text { telah ditentukan. }\end{array}$ \\
\hline $\begin{array}{c}\text { Chief } \\
\text { Engineer }\end{array}$ & $\begin{array}{l}\text { Kerusakan yang } \\
\text { disebabkan oleh } \\
\text { turunnya kualitas oli } \\
\text { (oil deteriorated). }\end{array}$ & $\begin{array}{l}\text { Mengganti oli } \\
\text { dengan kualitas } \\
\text { dengan standar } \\
\text { yang telah } \\
\text { ditentukan. }\end{array}$ \\
\hline $\begin{array}{c}2^{\text {nd }} \\
\text { Engineer }\end{array}$ & $\begin{array}{l}\text { Kerusakan yang } \\
\text { disebabkan oleh benda } \\
\text { asing (contoh } \text { nuts, } \\
\text { stone, washers } \text { etc) di } \\
\text { air intake system. }\end{array}$ & $\begin{array}{l}\text { Melakukan } \\
\text { perbaikan dan } \\
\text { pemeliharaan } \\
\text { pada setiap } \\
\text { komponen dari } \\
\text { turbocharge. }\end{array}$ \\
\hline $3^{\text {rd }}$ & $\begin{array}{l}\text { Kerusakan yang } \\
\text { disebabkan oleh benda } \\
\text { asing (contoh } \text { nuts, } \\
\text { stone, washers etc) di } \\
\text { air } \text { exhaust system. }\end{array}$ & $\begin{array}{l}\text { Melakukan } \\
\text { perbaikan dan } \\
\text { pemeliharaan } \\
\text { pada setiap } \\
\text { komponen dari } \\
\text { turbocharge. }\end{array}$ \\
\hline Cadet & $\begin{array}{l}\text { Kerusakan karena } \\
\text { temperatur terlalu } \\
\text { tinggi }\end{array}$ & $\begin{array}{l}\text { Menyesuaikan } \\
\text { sistem pendingin } \\
\text { pada turbocharge } \\
\text { dengan suhu } \\
\text { temperature } \\
\text { kamar mesin. }\end{array}$ \\
\hline
\end{tabular}

Dalam hasil wawancara, ditemukan 5 alasan mengapa mesin turbocharge bisa mengalami kebocoran. Saat inspeksi dilaksanakan, surveyor hanya menemukan kebocoran namun tidak mengetahui sebab kebocoran terjadi. Jadi hasil wawancara inilah yang menjadi acuan para awak kapal dalam memperbaiki kebocoran pada turbocharge.

b. Indikator lampu emergensi pada mesin penyuplai daya tidak bekerja saat di test (Tabel 4.2 audit item, section 15.6)

Lampu emergensi befungsi sebagai penerang jika terjadi suatu insiden di atas kapal. Lampu emergensi dapat menyala secara otomatis melalui daya dari mesin penyuplai. Lampu emergensi akan menyala secara otomatis saat keadaan kapal mengalami tuburkan, kandas, kebakaran dan kejadian lainnya pada saat lampu utama mati.

Saat surveyor melakukan tes lampu emergensi, ditemukan bahwa lampu tidak menyala saat dilakukan tes. Bukan hanya di tempat surveyor melakukan tes namun di keseluruhan ruangan dalam kapal lampu emergensi juga tidak menyala. Hal ini berasal dari mesin penyuplai daya yang tidak befungsi dengan baik.

2. Alat keselamatan kapal tidak memenuhi standar

Dalam bab 10 yang terdapat pada table 4.1 yang membahas tentang "Life-saving Appliances" yaitu bab yang membahas tentang standar keselamatan yang harus dipenuhi sebuah kapal, untuk menjamin keselamatan awak kapal bila terjadi bencana. Pada bab ini terdapat 2 temuan yang prioritasnya high yang artinya harus segera dilakukan tindakan, yaitu:

a. Selang pemadam kebakaran longgar (Tabel 4.2 audit item, section 11.2)

Kebakaran merupakan sebuah kejadian atau insiden yang sering terjadi diatas kapal. Saat kebakaran terjadi, diperlukan kesigapan untuk mematikan api secara cepat agar api tidak semakin menjalar yang dapat menyebabkan kapal meledak. Saat surveyor melakukan pengecekan selang pemadam kebakaran, ditemukan bahwa sambungan selang pemadam kebakaran longgar dan mengeluarkan air dari sambungan tersebut. Pihak kapal hanya mengamankannya dengan dililit oleh kabel tembaga yang menurut surveyor tidak aman. 


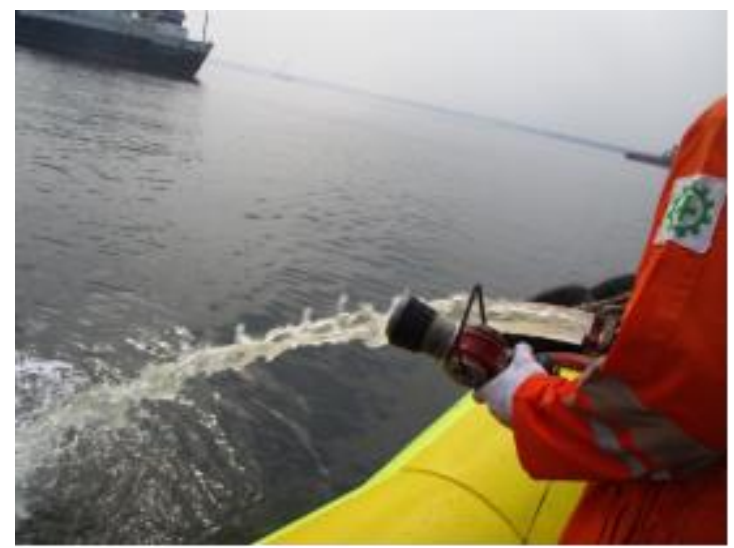

Gambar 3. Selang dilepaskan dari nozel

b. Baterai EPIRB dan HRU telah expired (Tabel 4.2 audit item, section 10.10)

Sebagaimana yang diketahui EPIRB atau Emergency Position Indicating Radio Beacon memiliki fungsi sebagai pengirim sinyal darurat saat kapal mengalami kecelakaan. Alat ini terletak pada anjungan kapal atau ruangan nahkoda, atau di geladak yang paling atas. Jadi jika kapal tenggelam atau mengalami kecelakaan lain, maka EPIRB ini biasanya dilemparkan ke laut agar mengapung, atau dibawa serta oleh nahkoda atau mualim agar jangan sampai tenggelam, dan alat akan bekerja secara otomatis bila terkena impact dengan air.

Sedangkan HRU berfungsi sebagai alat pemotong (pemutus) tali pengikat liferaft (Lashing Wire) dengan tempat kedudukan liferaft (Deck Cradle), sehingga unit liferaft tersebut bisa terlepas dari kedudukan liferaft (Deck Cradle) dan menggembang layaknya perahu karet penyelamat. Untuk penggunaan secara manual unit liferaft dilengkapi dengan tali penarik gas untuk mengembangkan liferaft yang terdapat pada sisi samping liferaft ataupun pada sisi depan liferaft.

Saat terjadi kecelakaan atau kapal tenggelam sinyal yang berasal dari EPIRB bisa ditangkap oleh stasiun radio pantai, radio milik ORARI (Organisasi Radio Amatir Republik Indonesia), radio pada pesawat atau kapal yang lewat. Tidak hanya titik koordinat kapal namun juga akan tercantum nama kapal dan nomor yang bisa dihubungi. Jadi jika terjadi kecelakaan dan EPIRB mati, otomatis kapal akan susah dideteksi dan dicari keberadaannya. Hal ini akan menyulitkan pengevakuasian para awak kapal.

Berdasarkan Deskripsi dan Analisis data yang telah dijelaskan diatas maka dibuatlah alternatif pemecahan masalah untuk permasalahan, peneliti mencoba memberikan suatu pemecahan masalah yang terbaik dari beberapa penjelasan yang telah diberikan.

1. Adanya kerusaan pada permesinan di kapal UB. Istana Laut a. Bagian kanan mesin utama pada turbo charge mengalami kebocoran (Tabel 4.2 audit item, section 15.1)

Dari hasil wawancara (table 4.3) yang dilakukan mengenai mesin kanan turbocharge yang mengalami kebocoran, peneliti memberikan pemecahan masalah terbaik yaitu ;

1) Melakukan perawatan secara periodik secara jam kerja

Perawatan Periodik dilakukan untuk pencegahan, biasaya terjadi dari pembukaan secara periodik mesin dan perlengkapan untuk menentukan apakah diperlukan penyetelan-penyetelan dan penggantian-penggantian. Jangka waktu perawatan biasanya didasarkan atas jam kerja dengan mengacu kepada Manual Instruction Book.

2) Menyiapkan spare part secara periodik

Saat terjadi kebocoran pada mesin utama yang disebabkan oleh sparepart yang sudah rusak, hal utama yang harus dilakukan adalah dengan mengganti spare part. Menyiapkan spare part secara periodik merupakan salah satu cara penanganan yang tepat guna mempercepat tindakan perbaikan.

b. Indikator lampu emergensi pada mesin penyuplai daya tidak bekerja saat di test (Tabel 4.2 audit item, section 15.6)

Ada 2 alasan mengapa lampu emergensi tidak menyala saat dilakukan tes yaitu, lampu emergensi yang memang mati atau ada masalah pada mesin penyuplai daya. Adapun pemecahan masalah yang terbaik yaitu;

1) Melakukan pengecekan secara berkala

Melakukan pengecekan secara berkala dilakukan agar tau bagaimana kondisi lampu emergensi. Pengecekan dapat dilakukan secara berkala tiap 2 minggu sekali atau 1 bulan sekali. Jadi jika sewaktu-waktu ada keadaan emergensi, lampu emergensi dapat digunakan.

2) Menyiapkan spare part agar indikator berfungsi Lampu emergensi yang tidak dapat menyala dikarenakan ada kerusakan di mesin penyuplai daya. Menyiapkan spare part dilakukan guna memudahkan awak kapal untuk melakukan perbaikan. Spare part yang disiapkan terlebih dahulu juga dilakukan agar awak kapal tidak perlu menunggu pengiriman dari pihak perusahaan pemilik kapal.

2. Alat keselamatan kapal tidak memenuhi standar

a. Selang pemadam kebakaran longgar. (Tabel 4.2 audit item, section 11.2)

Selang pemadam kebakaran yang mengalami kelonggaran pada sambungannya membuat pemadam api saat terjadi kebakaran tidak efektif. Hal ini dapat memperlambat pengerjaan 
pemadaman api. Pemecahan masalah yang dapat dilakukan adalah :

1) Mengganti kepala selang dengan yang baru Melakukan pergantian kepala selang dengan yang baru merupakan penangannan paling cepat yang harus dilakukan. Sebagaimana yang diketahui jika selang pemadam kebakaran yang mengalami kelonggaran pada sambungannya membuat pemadam api saat terjadi kebakaran tidak efektif. Hal ini dapat memperlambat pengerjaan pemadaman api.

2) Melakukan perawatan secara periodic secara waktu kalender

Perawatan secara periodik menurut waktu kalender adalah hal penting guna memperpanjang masa pemakaian selang. Perawatan biasanya dilakukan secara harian (daily), mingguan (weekly), bulanan (monthly), tiga bulan (quarterly), tahunan (yearly/annual survey) dan secara lima tahunan (special survey).

b. Baterai EPIRB dan HRU telah expired. (Tabel 4.2 audit item, section 10.10)

Telah ditemukan expirednya baterai EPIRB dan HRU yang sebagaimana digunakan sebagai pengirim sinyal darurat saat terjadinya kecelakan kapal.

Pemecahan masalah yang diberikan yaitu ;

1) Membuat matrix daftar peralatan yang memiliki masa expired

Diperlukan keseriusan para awak kapal untuk memantau / memaintenance masa expired barangbarang atau dokumen-dokumen diatas kapal. Hal ini bisa dilakukan dengan cara membuat matrix daftar peralatan atau dokumen yang memiliki masa expired. Maksimal 1 bulan sebelum masa expired peralatan atau dokumen habis, harus segera diberitahukan ke Kapten kapal yang kemudian akan diteruskan ke perusahan pemilik kapal tersebut.

Table 4. Contoh Matrix Peralatan dan Dokumen

\begin{tabular}{|c|c|c|}
\hline No. & Nama & Expired \\
\hline \multicolumn{3}{|c|}{ Peralatan } \\
\hline 1 & EPIRB & June 2018 \\
\hline 2 & Life Jacket & July 2019 \\
\hline 3 & Fire extinguisher & July 2019 \\
\hline \multicolumn{3}{|c|}{ Dokumen } \\
\hline 1 & ISM Certificate & 16 April 2022 \\
\hline 2 & $\begin{array}{l}\text { Cargo Ship } \\
\text { Safety } \\
\text { Construction } \\
\text { Certificate }\end{array}$ & $\begin{array}{l}14 \text { Desember } \\
2018\end{array}$ \\
\hline 3 & $\begin{array}{l}\text { Certificate of } \\
\text { Classification }\end{array}$ & $\begin{array}{c}22 \text { Desember } \\
2021\end{array}$ \\
\hline
\end{tabular}

2) Menyiapkan baterai yang baru

Menganti baterai dengan yang baru adalah penangan paling cepat yang harus segera dilakukan. Namun baterai juga harus disiapkan di atas kapal agar memudahkan pergantian jika sewaktu-waktu baterai habis.

Setelah dilakukan peninjauan terhadap alternatif pemecahan masalah yang telah dikemukakan di atas, yang dalam hal ini bertujuan untuk mencari pemecahan masalah yang terbaik serta efektif dan ekonomis sehingga dapat menguntungkan semua pihak yang terkait dalam menghadapi masalah tersebut. Dari setiap alternatif pemacahan masalah, terdapat kelebihan dan kekurangan.

Adapun evalusi dari alternatif pemecahan masalah tersebut adalah :

Kasus 1. Adanya kerusaan pada permesinan di kapal UB. Istana Laut

a. Bagian kanan mesin utama pada turbo charge mengalami kebocoran (Tabel 4.2 audit item, section 15.1)

1) Melakukan perawatan secara periodik secara jam kerja

Kelebihan :

a) Lebih mudah memantau perkembangan mesin

b) Mencegah terhentinya mesin yang tidak berencana

c) Memperpanjang masa pakai mesin

Kekurangan :

a) Jika rentang waktu perawatan terlalu pendek akan menggangu waktu operasi kapal

b) kemungkinan adanya kontaminan yang masuk kedalam system

2) Menyiapan spare part secara periodik

Kelebihan :

a) Memudahkan pergantian spare part karna sudah ada cadangannya

b) Tidak perlu menunggu pengiriman spare part jika sewaktu-waktu dibutuhkan

Kekurangan :

a) Ruang penyimpanan menjadi sempit dan berantakan

b) Jika spare part tidak dipakai-pakai akan menjadi rusak

c) Biaya yang dikeluarkan banyak

b. Indikator lampu emergensi pada mesin penyuplai daya tidak bekerja saat di test (Tabel 4.2 audit item, section 15.6)

1) Melakukan pengecekan secara berkala

Kelebihan :

a) Menjamin kesiapan lampu bila sewaktu-waktu ada keadaan emergensi

b) Menjamin keselamatan para awak kapal

c) Jika terjadi kerusakan dapat langsung ditangani sebelum terjadi keadaan emergensi 
Kekurangan :

a) Waktu operasi banyak terbuang

b) Kemungkinan terjadinya human error dalam proses pengecekan

2) Menyiapkan spare part agar indikator berfungsi

Kelebihan :

a) Memudahkan pergantian spare part karna sudah ada cadangannya

b) Tidak perlu menunggu pengiriman spare part jika sewaktu-waktu dibutuhkan

Kekurangan :

a) Spare part (lampu) jika lama disimpan akan rusak

b) Biaya yang dikeluarkan akan sia-sia jika spare part tidak terpakai

2. Alat keselamatan kapal tidak memenuhi standar

a. Selang pemadam kebakaran longgar. (Tabel 4.2 audit item, section 11.2)

1) Mengganti kepala selang dengan yang baru

Kelebihan :

a) Lebih mudah dan cepat penangannya

b) Memperpanjang masa pakai dari selangnya sendiri

Kekurangan :

a) Menambah biaya perbaikan

b) meningkatkan kesalahan yang timbul karena kekurangancermatan teknisi dalam memasang kembali komponen yang diperbaiki

2) Melakukan perawatan secara periodik secara waktu kalender

Kelebihan :

a) Biaya rendah dan dapat memperoleh keuntungan

b) Menjamin kesiapan alat bisa sewaktu-waktu dibutuhkan

c) Memperpanjang masa pakai

Kekurangan :

a) Jika rentang waktu perawatan terlalu panjang kemungkinan mesin akan mengalami kerusakan sebelum tiba waktu perawatan

b) Komponen yang masih baik dan menurut jadwal harus sudah diganti atau diperbaiki akan menimbulkan kerugian.

b. Baterai EPIRB dan HRU telah expired. (Tabel 4.2 audit item, section 10.10)

1) Membuat matrix daftar peralatan yang memiliki masa expired

Kelebihan :

a) Memudahkan awak kapal untuk memantau

b) Dapat dengan cepat menyiapkan spare part yang telah expired

c) Tidak terburu-buru untuk perusahaan mengirimkan spare part

d) Efisiensi biaya dalam pengiriman spare part

Kekurangan :
Jika tidak ada yang menjadi penanggung jawab matrix, spare part yang expired tidak akan terdeteksi dan akan sama saja EPIRB dan HRU tidak dapat berguna sesuai fungsinya.

2) Menyiapkan baterai baru

Kelebihan :

a) Mudah dalam melakukan pergantian karna baterai telah tersedia

b) Sebagai cadangan jika sewaktu-waktu baterai habis

Kekurangan :

Jika baterai yang telah disiapkan tidak digunakangunakan, baterai akan expired dan akan menimbulkan kerugian.

\section{KESIMPULAN}

Berdasarkan analisa mengenai standar kelayakan kapal melalui IMCA M149 survey pada kapal UB. Istana Laut, maka diperoleh suatu kesimpulan sebagai berikut :

1. Kerusakan yang terjadi pada permesinan kapal di kapal UB. Istana Laut disebabkan oleh bocornya bagian kanan mesin utama pada turbo charge dan indikator lampu emergensi pada mesin penyuplai daya tidak bekerja saat di test.

2. Upaya yang dilakukan oleh personil kapal untuk memenuhi standar keselamatan adalah melakukan perawatan secara periodik menurut waktu kalender untuk penanganan longgarnya selang pemadam kebakaran dan membuat matrix daftar peralatan yang memiliki masa expired untuk penangannya baterai EPIRB dan HRU yang telah expired.

Adapun saran - saran yang dapat menjadi bahan pertimbangan bagi pembaca untuk ke depannya, yaitu:

1. Sebaiknya perusahaan pemilik kapal yang dalam hal ini adalah PT. Barokah Gemilang Perkasa segera melakukan perbaikan kebocoran yang terjadi pada bagian kanan mesin utama pada turbo charge dan mengecek bagian mana pada mesin penyuplai daya yang menyebabkan tidak menyalanya lampu emergensi saya dilakukan test.

Namun pertimbangan dari segi biaya dan waktu, perusahaan harus melakukan sebuah manajemen perawatan untuk menjamin kesiapan mesin bila sewaktu-waktu mesin akan digunakan.

2. Para awak kapal harus melalukan manajemen perawatan seperti yang telah disarankan oleh surveyor dan juga memantau matrix daftar peralatan agar tidak ada lagi peralatan expired yang dibiarkan begitu saja. 


\section{DAFTAR PUSTAKA}

[1] Kamus Besar Bahasa Indonesia Edisi Keempat. 2008. Jakarta: PT. Gramedia

[2] Kosasih, Engkos dan Soewedo, Hananto. 2007. Manajemen Perusahaan Pelayaran (Jakarta : PT Raja Grafindo Persada)

[3] Peraturan Menteri Perdagangan Republik Indonesia No.14/M-DAG/PER/3/2006

[4] Suyono,R.P. 2007. Shipping : Pengangkutan Intermodal Ekspor Impor Melalui Laut Edisi Keempat (Jakarta: Percetakan Argya Putra)

[5] Undang-Undang Republik Indonesia Nomor 17 Tahun 2008 Tentang Pelayaran

[6] Wikipedia . 2015. Pengertian Peraturan. https://id.wikipedia.org/wiki/Peraturan, 15 Juni 2015 